\title{
OBSERVACIONS SOBRE LES RELACIONS HISTORIQUES I ARTÍSTIQUES \\ ENTRE CLUNY I LA PENÍNSULA IBÈRICA \\ (SEGLES X-XII)
}

\author{
XAVIER BARRAL I ALTET \\ Universitat de Rennes (França)
}

\begin{abstract}
SUMARI
I. La qüestió històrica.- 1. Zona catalana.- 2. Zona castellano-lleonesa.-

II. La qücstió artística. - 1. Zona catalana.- 2. Zona castellano-lleonesa.
\end{abstract}

Aquest text és fruit d'una doble circumstància: per una banda, el simposi celebrat a Girona sobre l'arquitectura a Catalunya entre els segles IX-XI, on vaig presentar una ponencia més especffica sobre les relacions entre Catalunya, el Midi de França i la Borgonya entre el 950 i el 1040; i, per una altra, la trobada informal organitzada pel CNRS el mes de setembre de 1993, a Cluny, en la qual vaig presentar un estat dels estudis cluniacencs pel que fa a la Península Ibèrica ${ }^{1}$. Més particularment en aquest camp, paradoxalment tan poc estudiat, la problemàtica se centra en el major o menor grau de presencia de Cluny a les diverses zones de la Península Ibèrica durant l'Edat Mitjana, sobretot romànica, i en quina ha estat la repercussió artística, a la Península Ibèrica d'aquesta presència. És evident que només estudis monogràfics molt detallats sobre cada monestir o sobre aspectes precisos de la relació amb Cluny permetran de dibuixar-ne un dia

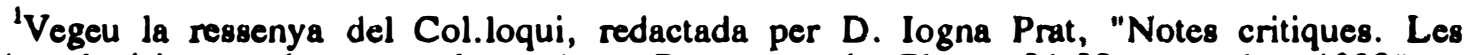
études clunisiennes dans tous leurs états. Rencontre de Cluny, 21-22 septembre 1993", a "Revue Mabillon", Nouvelle série, V (1994), pp. 233-265.
}

"Anuario de Estudios Medievales". 24 (1994) 
un panorama general; mentre que en el camp de l'art no es podrà fer un balanç de les influencies exercides directament o indirecta per Cluny fins que no s'hagin estudiat el major nombre possible de casos concrets en els quals s'aprecien relacions artístiques tant amb els prestigiosos edificis de Cluny i amb la seva decoració com amb les emanacions més properes de la seva irradiació. Ara per ara, aquest breu balanç i aquests elements de problemàtica podrien servir d'orientació per a construir un veritable programa d'investigació sobre el tema.

\section{LA QÜESTIÓ HISTÒRICA}

En línies generals es pot afirmar que la introduccio de Cluny a la Península Ibèrica ha estat a nivell historic molt poc estudiada a nivell historic. Exceptuant algunes aportacions individuals, que més tard ressenyaré, la majoria d'estudis que hi fan referencia són visions conjuntes o evolutives sobre la història de l'església ${ }^{2}$, del monaquisme ${ }^{3}$ i de la implantació del benedictisme a Espanya ${ }^{4}$; o bé monografies de determinats monestirs ${ }^{5}$, a les quals cal afegir la publicació de diversos aplecs documentals. Fins i tot,

\footnotetext{
${ }^{2}$ Com, per exemple, Historia de la iglesia y de las instiluciones eclesiásticas, "Trabajos en homenaje a F. Valls i Taberner", Málaga, 1990.

${ }^{3}$ M.P. CoCherIL, Etudes sur le monachisine en Espagne et au Portugal, París, 1966; "I Col.loqui d'Història del monaquisme català", Santes Creus, 1966, 2 vols. (1967-1969); A. PLADEVALI, Els monestirs calalans, Barcelona, 1970; "II. Col.loqui d'Història del monaquisme català", Santes Creus, 1970, 2 vols. (1972-1974); A. LINAGE CONDE, El monacato en España e Hispanoamérica, Instituto de Historia de la teología española (Subsidia, 5), Salamanca, 1977; A. MASOLJVER, História del monaquisme cristid, Abadia de Montserrat, 1980; J.A. GARCIA DE CORTAZAR, Las formas de institucionalización monástica en la España medieval, a "Codex Aquilarensis. Cuademos de Investigación del Monasterio de Santa Maria la Real", 2 (agosto 1989), pp. 63-81.

'Cal destacar en aquest camp els estudis d'A. LINAGE CONDE, Los origenes del monacato benedictino en la Peninsula lbérica, II, Difusión de la "Regula Benedicti", León, 1973; i La difusión de la Regla de San Benito y la sociedad española en la Alta Edad Media, Acción Social de la Orden Benedictina. XV Centenario de San Benito. "Anales de Moral Social y Económica", LXV, Centro de Estudio Sociales del Valle de los Cá́dos, Madrid, 1982.

SA.M. Albareda, J. Masso't I Muntaner, Historia de Montserrat, Publicacions de l'Abadia de Montserrat, 1972; E. JUNYENT, El inonestir romìnic de Santa Maria de Ripoll, Barcelona, 1975; R. d'ABADAL, Com neix $i$ com creix un monestir pirinenc abans de l'any mil: Eixalada-Cuixd, Publicacions de l'Abadia de Montserrat, 1954; C. BARAUT, El monestir de Sant Sadurni de Tavèmoles $i$ els origens del monaquisme benedicti al comsat d'Urgell, "Studia Monastica", XXII-2 (1980), pp. 254-259.
} 
dins d'aquest corrent historiogràfic, generalitzador i normalment divulgatiu, encara hi trobem a faltar un estudi sistemàtic de cadascun dels diversos ordes religiosos.

El que sí que reflecteix la bibliografia apuntada, tanmateix, és la conveniencia de separar territorialment la Península Iberica, ateses les diferents circumstàncies historiques de cadascuna de les àrees, a l'hora d'estudiar la recepció i el posterior desenvolupament de la reforma cluniacenca. Aixı, amb l'excepció de Sánchez Albornoz, que sempre particularitza el cas iberic $^{6}$, la majoria d'historiadors estan d'acord a delimitar uns ritmes $i$ unes evolucions diferents entre la zona catalana i la castellano-lleonesa. Seguint, doncs, aquesta divisió, intentaré exposar i valorat les diverses aportacions, més per temes i per successió cronologica dins d'aquests que no pas per l'ordre exhaustiu de publicació dels treballs.

\section{Zona catalana}

Com a premissa principal, es pot afirmar que l'abadia borgonyona no va jugar a Catalunya el paper fonamental que tradicionalment la historiografia ha atribuiit a la resta de la Península Iberica. La primera diferencia respecte a aquesta és la primerenca adopció de la Regla de sant Benet, documentada ja al final del segle VIII, gràcies sobretot a la pertinença a l'imperi carolingi. Aquest aspecte ha estat investigat ampliament per $\mathrm{A}$. Linage Conde el qual arriba a afirmar que "ya en el siglo IX Cataluña no era diferente del resto de Europa central i occidental"7, mentre que Portugal, per exemple, no rebé l'orde de sant Benet fins la penetració de la reforma cluniacenca al segle XI. Queda, pero, per confirmar si la benedictinització a la Marca Hispànica fou total o be si alguns monestirs continuaren amb regles mixtes, com ho sembla estimar Manuel Riü.

Allò que va cridar ràpidament l'atenció als investigadors, com per exemple a P.F. Kehr ja a l'any 1927, fou, en paraules seves, la ràpida ro-

${ }^{6} \mathrm{C}$. SANCHEZ Albornoz, España. Un enigma histórico, Buenos Aires, 1962.

${ }^{7}$ A. LiNAGE CONDE, op. cit., 1973, p. 499.

${ }^{8}$ M. RIU I RIU, Monacato y colonización rural en la Cataluña altomedieval, "Segundo Seminario sobre el Monacato", Aguilar de Campóo, agosto de 1988. Publicat a "Codex Aquilarensis. Cuadernors de Investigación del Monasterio de Santa María la Real", 2 (agosto 1989), p. 88. 
manització de Catalunya9; és a dir, els nombrosos i primerencs -per la decadencia i manca de poder en que es trobava la Santa Seu- privilegis d'exempcio pontificis que reberen alguns monestirs catalans ${ }^{10}$. De fet, la traducció que féu Ramon d'Abadal d'aquest estudi al català promogué les seves propies investigacions posteriors sobre la historia de l'església a Catalunya ${ }^{11}$. El fet és que només un any després que Agapit II concedís una nova butlla a l'abat Aymard de Cluny, el monjo Sunyer del monestir de Sant Miquel de Cuixà marxà a Roma i aconsegur l'exempció i la lliure elecció de l'abat de mà del mateix pontifex. Aquesta accí es repetf́ en nombroses ocasions, com per exemple l'any següent, i quedaren deslliurats molts monestirs de l'autoritat episcopal. Ramon d'Abadal, el qui més detalladament ha estudiat aquest període, creu que l'acte del monjo Sunyer de Cuixà només es pot explicar pel coneixement que aquest devia tenir de les noves concepcions monàstiques i fins i tot de la butlla atorgada a Cluny ${ }^{12}$. Els contactes amb l'abadia borgonyona proliferaren. L'any 965 , el comte Sunifred de Cerdanya anà a Lézat, abadia regida per Cluny, buscant un nou abat per a Cuixà; Garf fou des d'aleshores abat de Lézat i Cuixà. Altrament, la primera menció directa a l'abadia borgonyona dins la documentació conservada és la del testament del mateix Sunifred, on llega "deu peces de diners d'Ausona, de Barcelona o de Girona, que fareu donat al cenobi de Sant Pere de Cluny"13. La nova orientació del monaquisme català vers Roma va ser aglutinada al final del segle $\mathrm{X}$ i començament del segle XI, amb l'intermedi forçós de la ràtzia d'Almansor, per dos dels personatges més àmpliament estudiats dins la historiografia medieval en llengua catalana: l'abat Garl i el bisbe Oliba. Arran dels estudis de Ramon d'Abadal -que considera l'individu motor de la historia-, l'abat Garl ha estat interpretat com "l'animador espiritual" d'un moviment congregacionista, amb les cases

'P.F. KEHR, El Papat i el principat de Catalunya, "Estudis Universitaris Catalans", 12 (1927); 13 (1928).

${ }^{10} \mathrm{P} . \mathrm{F}$. Kehr arriba a afirmar que Catalunya va rebre al final de segle $\mathrm{X}$ i principi del segle XI més butlles pontifícies que cap més regió o país d'Europa.

"Per emmarcar la labor historiografica de Ramon d'Abadal es pot recomanar la lectura de: Ramon d'Abadal $i$ de Vinyals. Commemoració del centenari del seu naixement, Generalitat de Catalunya, 1989.

${ }^{12} R$. d'ABADAL, $L$ 'esperit de Cluny $i$ les relacions de Catalunya amb Roma $i$ la ltalia en el segle X, "Studi Medievali", 3a sèrie, II-1 (Spoleto, 1961), pp. 8-9.

${ }^{13} \mathrm{El}$ testament de Sunifred de Cerdanya és transcrit integrament a: Ramon d'ABADAL, 1954, op. cit., doc. núm. 92. 
de Lézat, Cuixà, Sant Hilari de Carcassona, Sant Pere de Caunès i Santa Maria d'Alet, que introduïa l'esperit de renovació monàstica aportat per Cluny a Catalunya. Tanmateix, seguint la tradicio cluniacenca, cada monestir tenia un segon abat resident; aixo, sumat a la manca de lligam jurídic entre ells, comportà que amb la mort de Garl, morís també la seva obra.

A. Mund $\sigma^{14}$, amb l'objectiu d'analitzar l'autentic ofici de Cluny a l'est dels Pirineus (que de bon començament ja considera plutôt modeste), estableix tres moments diferents. El primer correspon a la reagrupació monàstica que, a imitació de Cluny, endagaren algunes abadies gràcies als seus promotors que en recolliren l'esperit i l'hi introduïren. Dins d'aquest grup situa l'abat Gar! i l'abat Oliba, entre altres. Igual com d'Abadal, no creu en l'existencia de lligams juŕ́dics entre els diversos centres, sino que en el cas de l'abat Oliba, per exemple, els contactes podien establir-se mitjançant relacions amicals $i$ consells espirituals ${ }^{15}$. A diferencia de la que es refereix a l'abat Gari, A. Mundo remarca que no s'ha trobat un sol mot que faci menció a Cluny a la documentació oficial de l'abat i bisbe Oliba.

Amb la desaparicio d'aquests personatges i amb la represa de l'apropiació laica dels béns eclesiàstics, s'inicia, segons A. Mundo, el segon moment, aproximadament durant la segona meitat de segle XI, quan diversos patrons lleguen els seus monestirs a abadies estrangeres reformades, sense un pla preconcebut. És en aquest moment que s'insereix la possible penetració directa de Cluny al sud-est dels Pirineus. Encara no ha estat possible cercar una explicacio raonable del perque l'abadia borgonyona refusà les donacions de diversos nobles catalans ${ }^{16}$. A. Mundo argumenta raons de tipus político-economic, com l'aprensió de Cluny davant una nova perspectiva de croada o la política de paries de Ramon Berenguer ${ }^{17}$, sense trobar-les pero del tot satisfactories. Tanmateix, Ch.J. Bishko, en impor-

\footnotetext{
${ }^{14} \mathrm{~A}$. MUNDO, Moissac, Cluny et les mouvements monastiques de l'Est des Pyrenées du XZ au XIIZ siecles, "Annales du Midi", 75 (1963)

${ }^{15}$ A causa, precisament, de la relació tan flexible que mantingué amb els altres centres religiosos, R. d'Abadal i A. Mundó no semblen coincidir a l'hora de delimitar les comunitato de les quals l'Oliva fou directament abat.

${ }^{16}$ Amau Mir de Tost, partícip de la reconquesta a la vall del Segre, després d'aconseguir privilegis d'exempció pontificis per a Sant Pere d'Ager, l'any 1066 oferí a l'abat Hug de Cluny el monestir amb els seus béns i la lliure elecció d'abat. L'abadia borgonyona no tan sols refued aquesta donació sinó tambe la de Girabert Mir d'Olèrdola, que, en el seu testament, llegà alguns castells $\mathrm{i}$ terres de la seva possessió a Cluny.
}

${ }^{17}$ A. MUND6, op. cit., pp. 561-563. 
tants estudis sobre la influencia de Cluny a Portugal, Lleo i Castella, ha analitzat les donacions denegades per Cluny des d'un nou punt de vista historic, com la guerra de Barbastro (1064) i l'oposada aliança monàrquica que hi jugaren el papat i Cluny. D'aquesta manera, l'historiador nord-americà recalca que els territoris llegats a Cluny per Arnau Mir de Tost i Gibert Mir d'Olèrdola abans havien estat sota la protecció pontifícia; pero que, davant l'aliança del Regne d'Arago amb Alexandre II, ambdós volgueren protegir llurs àrees frontereres mitjançant la presència cluniacenca ${ }^{18}$. La no concreció d'aquestes cessions tant podria explicar-se per l'oposició dels familiars més proxims com de la mateixa església romana, anterior beneficiària.

Les úniques possessions directes de Cluny als comtats catalans foren el monestir de Sant Pere de Casserres i els priorats de Clara i Corbera. Quan Bernat II de Besalú llegà el 1078 els monestirs de Sant Pere de Camprodon, Sant Pau del Fenollet i Santa Maria d'Arles de Tec a Cluny, ho féu amb l'abadia de Moissac (des del 1052 priorat de Cluny) com a mitjancera. Aquest fet demostra la tesi d'A. Mundo, reflectida en el tercer moment per ell definit, segons la qual la reagrupació monàstica adquireix en aquest moment una base local, $i$ en el cas de Cluny l'abadia mare estava molt allunyada dels comtats catalans ${ }^{19}$.

En els darrers anys Manuel $\mathrm{Riu}^{20}$ ha anat investigant el paper que jugaren els monestirs en el repoblament i l'estructura territorial de la Catalunya Vella. A través dels seus estudis demostra com, durant la segona meitat del segle XI, foren les canoniques que guanyaren adeptes davant els monestirs i que, en el cas del monacat, i més tenint en compte l'escassa presència directa de Cluny a Catalunya, aquest hagué d'esperar una nova reforma, la del Císter, per participar activament en el repoblament de la Catalunya Nova.

\footnotetext{
${ }^{18} \mathrm{Ch}$. J. BISHKO, Spanish and Portuguese inonastic History 600-1300, Londres, 1984.

${ }^{19} \mathrm{~A}$. MUNDO, op. cit., pp. 564-565. També A. MUNDO, Monastic movements in the East Pyrenees, a Clunic Monasticisin in the Central Middle Ages, Londres, 1971

${ }^{20} \mathrm{M}$. RIU I RJU, La inserció dels monestirs en la societal i l'economia catalanes (segles XVIII-XII), "Quadems d'Estudis Medievals", I-8 (1982), pp. 467-472; Monacato y colonización rural en la Catalunya altomedieval, "Codex Aquilarensis. Cuadernos de Investigación del Monasterio de Santa María la Real", 2 (agosto 1989), pp. 85-107.
} 


\section{Zona castellano-lleonesa}

La penetració de Cluny a la resta de la Península Iberica fou bastant més tardana; tot i aixi, ha estat molt més atesa per la historiografia a causa del seu caràcter directe i de la intervenció que tradicionalment hom li ha atribuit en qüestions polítiques i religioses, com la reconquesta o l'afiançament del caml de peregrinacio a Santiago de Compostela. Tanmateix, la bibliografia recent tendeix a relativitzar el paper jugat per l'abadia borgonyona i a augmentar la responsabilitat de la monarquia lleonesa.

L'esperit de Cluny en la nova orientació eclesiàstica dels regnes cristians espanyols sembla que és indiscutible. Al llarg del segles IX i X, i tambe durant bona part del segle $\mathrm{XI}$, pervivien en els territoris cristians cel.lules cenobítiques de caràcter repoblador, en les quals les pautes d'observànça responien més a un codi de vida en comú que no pas a una reglamentacio juŕ́dica. Aquest fet no vol dir que la Regla de sant Benet no fos coneguda, sinó que era una opció més al costat, per exemple, de les de sant Isidor o sant Fructuós, i que no podia arrelar fins que no arribes institucionalitzada a través de Cluny. Tant J. A. García de Cortàzar com A. Linage Conde s'han preguntat sobre el perque d'aquest retard. El primer afirma que la benedictinització suposava un canvi de mentalitat, significava posar fi al amb el pactisme visigot, amb la jurisdiccio del bisbe sobre el monestir, amb els monestirs familiars i dobles $i$, també, un canvi en la litúrgia hispànica ${ }^{21}$; el segon ho atribueix més a causes d'aïllament o d'ignorància dels nous temps europeus $i$ a un nivell de vida molt poc propici a la implantacio del luxe 22 . De fet, Cluny devia el seu prestigi i riquesa a l'exempcio davant l'ordinari i a la dependencia directa del papat.

Les primeres donacions a Cluny en els territoris més occidentals de la Península Iberica s'esdevingueren durant el regnat de Sancho III el Mayor de Navarra, el qual, sota els consells de l'abat Oliba i de l'abat Ponç de Tavernoles (bisbe d'Oviedo entre el 1028-1035), cedf a l'abadia borgon. yona el monestir aragones de San Juan de la Peña (1028), seguit dels navarresos de Leyre i Irache i del castella d'Oña, entre d'altres. Els anys 60 del nostre segle $\mathrm{e}^{23}$ ja es va debatre, en oposició a la interpretació més tradicio-

\footnotetext{
${ }^{21}$ J.A. GARCla dE CORTAZAR, op. cil., p. 70.

${ }^{22}$ A. LINAGE CONDE, op. cit., 1973, p. 45.

${ }^{23}$ C. SANCHEZ ALBORNOZ (op. cit., pp. 280-283) afima que l'arribada dela monjos
} 
nal, que l'ingrés de Cluny a l'oest de la Península fos degut a la seva intencio d'explotar el camı de Santiago a la zona de La Rioja. De fet, l'escassa documentacio que es conserva del segle XI, ens mostra el monarca navarrès com a màxim responsable i protector del benedictinisme cluniacenc. Aixf, els primers contactes amb Cluny semblen respondre a la relacio personal del monarca amb l'abat Odilo per tal d'anar introduint els costums i l'espiritualitat benedictina en els seus territoris ${ }^{24}$. Cal, doncs, desvincular aquesta primera via de relacio amb Cluny de la que a mitjan segle XI es donà al territori lleonès.

Els vincles més intensos entre l'abadia borgonyona i l'incipient regne de Castella i Lleo es troben durant els regnats de Fernando I i Alfonso VI. Qui millor ha estudiat aquesta relacio ha estat Charles J. Bishko ${ }^{25}$, que arriba a precisar un canvi de rumb, caràcter $\mathrm{i}$ intencionalitat enmig de l'aliança que ambós monarques mantingueren amb Cluny. La seva anàlisi parteix de dues premisses bàsiques: la primera, la política enfrontada entre els abats cluniacencs i els papes reformistes "gregorians"; i la segona, el sistema d'aliances competitives que establiren ambdós amb les monarquies hispàniques.

La tesi que ha sostingut el professor americà és que, pels anys 1063 i 1077, Fernando I i Alfonso VI respectivament passaren de mantenir una relacio d'amicitia a una de coniunctio amb l'abadia de Cluny; es passava, doncs, d'una relació fraternal, basada en la cessio de diversos centres religiosos, a un vincle de clientela, basat en el pagament d'un cens de mil, primer, i de dos mil, després, mectales d'or. Quines són les circumstàncies que comportaren aquest canvi? Responia aquest als interessos de l'abadia borgonyona de participar en la Croada i Reconquesta espanyola o d'organitzar i promoure les vies de peregrinació? Contràriament a aquestes hipdtesis, Charles J. Bishko afirma, potser de manera bastant categorica, que "la alianza con Cluny constituyó un elemento esencial de éxito para la expansión dinástico-imperial del estado castellano-leonés". En ambdós casos el canvi de relació respon al perill que suposava per a la monarquia lleonesa el nou interès del papat per a intervenir en la reconquesta espanyola.

cluniacencs fou a causa de les ànsies d'europeització de Sancho el Mayor i del seu anhel de salvar el clergat de la crisi moral i cultural que l'assolava.

${ }^{24} \mathrm{Ch}$. J. BishKo, Fernando I y los origenes de la alianza castellano-leonesa con Cluny, "Cuadernos de Historia de Espana", XLVII-XLVIII (1958), pp. 31-135.

${ }^{25}$ Ens remetem als articles de Ch.J. Bishko recollits al volum citat a la nota 18 . 
Quan Ramiro I d'Aragó s'alia amb la Santa Seu, trobem que determinats nobles catalans, que tenien possessions a la zona fronterera de Barbastro, les volen llegar a Cluny ${ }^{26}$, $\mathrm{i}$ és en aquest mateix moment que Fernando I atorga el cens anual a l'abadia francesa. Una situació semblant es produeix en temps d'Alfons VI, davant el reclam de Gregori VII sobre la sobirania de la península i de l'atac a l'església castellano-lleonesa reclamant l'abolició del ritus hispànic, Alfons VI: duplica el cens per a l'abadia borgonyo$\mathrm{na}^{27}$.

Per a Cluny aquest cens anual d'origen hispànic suposà un factor primordial per al creixement material de l'abadia mare ${ }^{28}$ i també la possibilitat de crear priorats en zones hispàniques, que estigueren concentrats, com ho analitzaré a l'apartat artístic, sobretot dins els territoris de la Corona lleonesa. Però no és pot oblidar que l'estreta relació amb el Regne de Castella i Lleó significà també l'apogeu del poder temporal de l'abadia a la península. És innegable que Cluny tingué molt a veure amb la nova orientació eclesiàstica dels regnes cristians espanyols; però aquesta no es donà tan sols a nivell monàstic sinó que la majoria de prelats pontificis de les zones reconquerides foren monjos formats a Cluny. Potser l'exemple més significatiu és el Bernardo de Sédirac, antic monjo de Cluny i abat de Sahagún, que fou nomenat arquebisbe de Toledo. Circumstàncies similars es donaren a les seus episcopals de Pamplona, Palencia, Segovia, Osma, Salamanca o Santiago. Fou aixı, precisament, com es reemplaçà a Portugal el monaquisme iberic, de tipus pre-carolingi, pel d'origen benedictr, a partir del darrer quart del segle XI. Les diocesis, per exemple, de Braga i Porto entraren en mans de prelats estrangers, normalment cluniacencs; el poder temporal, gràcies a la política d'aliances matrimonials d'Alfons VI, acabà en mans del duc Enric de Borgonya (1094-1114)29.

\footnotetext{
${ }^{26}$ Ens referim a les cessions que Amau Mir de Tost i Girabert Mir d'Olerdola feren a l'abat de Cluny i que han estat exposades a l'apartat sobre Catalunya.

${ }^{27}$ Tanmateix, el monarca espanyol hagué de cedir a les prescripcions pontíficies, tot fa suposar que sota la recomenació de l'anomenat papa negre; i el 1080 en el Concili de Burgos s'implantà la litúrgia romana a tots els territoris cristians de la Península Iberica.

${ }^{28}$ La gran construcció de Cluny III es degue en part als ingressos procedents de la monarquia lleonesa. Fins i tot, Kenneh John Conant afinma que el lleo heràldic que es troba a l'hospici, construït entre 1077-1079, es una mostra de la gratitud de l'abadia envers Alfons VI.

${ }^{29} \mathrm{~J}$. MatToso, Le monachisme ibérique el Cluny. Les monasteres du diocèse de Porto l'an mille d 1200, 1968.
} 
El paper de Cluny a la Península Ibèrica els regnats d'Urraca i d'Alfons VII no ha estat encara prou estudiat. Si més no, es pot aventurar que aquests no pogueren mantenir l'alt cens atorgat a Cluny i que retornaren a la pràctica habitual de donar, quasi anualment, un monestir reial a l'abadia mare ${ }^{30}$. Altrament, aquest període ja correspon a la penetracio cistercenca en terres hispaniques.

Darrerament, la revista "Gesta", especialitzada en art medieval, ha dedicat tot el volum vint-i-sete, corresponent a l'any 1988, a l'art relacionat amb Cluny i la seva difusio europea. John Williams ${ }^{31}$, en un article que comentaré a bastament dins la qüestio artística, relativitza, fent-se resso dels estudis ressenyats, l'ofici de Cluny en la reconquesta i l'organitzacio del camí de Santiago i atribueix majors responsabilitats a la mateixa iniciativa hispànica.

\section{LA QÜESTIÓ ARTÍSTICA}

Des del començament es ve afirmant que l'abadia borgonyona fou qui organitzà i promocionà els camins de peregrinació a Santiago de Compostela i que a través de les dites vies fou com ingressà l'art romànic madur a la Península Ibèrica. Tanmateix, la historiografia recent, sobretot la dels anys vuitanta i noranta, va reconsiderant diverses qüestions que fins ara eren considerades inamovibles.

En primer lloc, resulta difícil demostrar la primacia de Cluny dins dels camins de peregrinacio; ja les investigacions d'Élie Lambert van constatar que molts altres ordes tenien nombrosos priorats en aquestes vies ${ }^{32}$. De fet, els estudis recents de John Williams ${ }^{33}$ demostren que només una de les cinc esglésies de peregrinacio, Saint-Martial de Limoges, fou plenament cluniacenca ${ }^{34}$, mentre que a les altres només s'hi donà un intent 0

\footnotetext{
${ }^{30}$ Alfons VIl cedi, per exemple, a Pere el Venerable els monestirs de Sahagun (1132) i San Pedro de Cardeña (1142)

31J. WILuAams, Cluny and Spain, "Gesta. Intemational Center of Medieval Art", XXVII$1 / 2$ (1988), pp. 93-101.

${ }^{32}$ M.E. LAMBERT, Ordres et confréries dans l'histoire du pelegrinage de Compostelle, "Annales du Midi", LV (1943), p. 369.

${ }^{33}$ J. Willuams, La arquitectura del Camino de Santiago, "Compostellanum. Revista del Centro de Estudios Jacobeos", XXIX-3/4 (1984), pp. 267-290 i op. cit., 1988.

${ }^{34}$ Saint-Martial de Limoges fou cedida a Cluny l'any 1062. Se sap que l'any 1053 patí un
} 
presencia temporal. És cert que, de les set primeres dependències cluniacenques a Espanya, tres -San Zoil de Carrión, Santa Maria de Nájera i Santa Coloma de Burgos $^{35}$ - estaven emplaçades en el cami de Santiago, pero la localització d'aquestes donacions depenia més dels interessos hispanics que no pas dels borgonyons. Aquesta desvinculació entre les vies de peregrinació i l'abadia borgonyona ha inspirat un novedós article d'O.K. Werckmeister ${ }^{36}$ quant al seu enfocament, on sosté la hipdtesi que les característiques arquitectoniques de Cluny III responien a un intent, per part de l'abat Hug, d'obrir l'església a una audiència laica i aix́ encapçalar una de les vies de peregrinatge; aquest intent d'absorció l'associa amb l'interès per part de l'abadia borgonyona de protegir legalment i política les esglésies de peregrinació de Saint-Sernin de Toulose i Sainte-Foi de Conques.

La segona afirmacio, apuntada en un principi, pressuposa dues premisses davant les quals hom és bastant esceptic. La primera és la identificació de l'anomenat art cluniacenc amb l'art benedict' i, per extensio, amb l'art plenament romànic ${ }^{37}$; i la segona, la concepçió dels camins de peregrinació com a vies per on circulaven els nous corrents artístics que es difonien a altres contrades ${ }^{38}$. Serafín Moralejo, en els seus darrers estudis $^{39}$, és molt crític amb aquestes afirmacions, considerant-les abusives $i$

incendi, però és difícil de precisar si el pla de reconstrucció s'inicià durant el domini borgonyó.

${ }^{35}$ Cedides a Cluny els anys 1076, 1079 i 1081, respectivament.

${ }^{36}$ O.K. WerCKMEISTER, Cluny III and the Pilgrimage to Santiago de Compostela, "Gesta. Intemational Center of Medieval Art, XXVII-1/2 (1988), pp. 103-112; i abans a Artistes, artisans et production artistique au Moyen Age, X. BARRAL. I ALTET, ed., II, París, 1987, pp. 135-142.

${ }^{37} \mathrm{El}$ primer de parlar d'un art pròpiament cluniaccnc fou Viollet-le-Duc, que afirmà que els monjos cluniacencs eren enviats a altres monestirs ainb traces arquitectòniques que no podien modificar. La idea d'una unitat cultural dins de l'art cluniacenc fou represa a les investigacions de Joan Evans, que arribà a determinar-ne diversos grups (Romanesque Architecture of the Order of Cluny, Cambridgc, 1938 i Cluniac Art of the Romanesque Period, Cambridge, 1950).

${ }^{38}$ Foren E. MÁLE (L'art religieux du XIlè siècle en France, Paris, 1923) i A.K. PORTER (Romanesque Sculpture of the Pilgrimage Roads, 1923) aquells qui forjaren, a imitació del que passava amb els temes literaris, aquesta imatge de les vies de peregrinació com els camins pels quals es difonia el nou art romànic de la mà dels peregrins.

${ }^{39} \mathrm{~S}$. MORALEJO, Modelo, copia y originalidad, en el marco de las relaciones artísticas hispano-francesas (siglos XI-XIII), "Ve Congrés espanyol d'Història de l'Art" (1984), I, Barcelona, 1986, pp. 89-112; Artistas, patronos y público en el arte del Carnino de Santiago, "Compostellanum. Revista del centro de Estudios Jacobeos", XXX-3/4 (1985), pp. 395-430; Cluny y los origenes del románico palentino. El contexto de San Martin de Frómista, "Jomadas sobre el arte de las ordenes religiosas en Palencia" (24 al 28 de juliol de 1989), Palencia, 
vulgaritzadores. Per a ell, més que de la introducció del romànic a Espanya a través de les vies de peregrinacio, s'hauria de parlar de la integració d'Espanya dins de l'àmbit en què es gestava el romànic ple. En lloc d'un producte acabat, els regnes cristians occidentals en reberen les premisses, les materies primeres $i$, sens dubte, en un primer moment, els artistes més qualificats.

Aquests darrers anys, a banda de desmentir-se pressuposits preestablerts, es van concretant les relacions artístiques, directes o indirectes, entre Cluny i els regnes cristians occidentals. L'escassa incidencia historica de l'abadia borgonyona a Catalunya i la seva desvinculació de les hipotetiques vies d'influencia cluniacenca fan suposar que els contactes artístics directes devien haver estat mínims i, fins i tot, inexistents. Si més no, és necessari que proliferin aquests estudis puntuals per a poder realitzar $a$ posteriori una valoració de les veritables dependencies artístiques de la Península Ibèrica amb l'abadia de Cluny.

\section{Zona catalana}

Les relacions artístiques entre Cluny i Catalunya sovint han estat exagerades, atès l'esperit congregacionista d'arrel cluniacenca que implantaren homes com l'abat Garl o l'abat Oliba. Amb l'arquitectura pre-romànica o el primer romanic caldria provar de fer un estudi concret, de formes 0 d'estructures, comparant-les amb l'església de Cluny $\mathrm{II}^{40}$. Aixi, per exemple, sabem que la construcció de l'església de Sant Miquel de Cuixà s'inicià l'any 956, tot just abans de l'arribada de l'abat Gaŕ procedent de Lézat, domini cluniacenc. Aportà el nou abat alguna novetat artística, relacionada amb el nou prestigi de Cluny, al monestir que s'anava construint i que fou consagrat l'any 974? Quan l'abat l'Oliba, durant el primer terç del segle $X I$, endegà una nova ampliació del temple de Cuixà, edificant una mena de capçalera rectangular entre les dues absidioles primitives que hi havia a banda i banda de l'altar major, s'inspirava en els corredors laterals que

1990, pp. 7-27; i Cluny et les débuts de la sculpture romane en Espagne, a Le gouvernement d'Hugues de Sernur d Cluny, Cluny, 1990, pp. 405-434.

${ }^{40}$ La primera església de l'abadia de Cluny es consagrà el 927 ; pero, a causa del creixement de la comunitat, sembla que aquesta aviat resulta insuficient i que, l'any 955 , e'inicia una renovació total, sota l'abadiat de Mayeul. L'any 981 es consagrà l'església de Cluny II i vers, el 1010, tota estava coberta amb voltes de canó. 
envoltaven la capella major de l'església abacial de Cluny $\mathrm{II} ?^{41} \mathrm{El}$ cos circular occidental de Cuixà, té quelcom a veure amb les rotondes de Borgonya? ${ }^{42} \mathrm{Cal}$, doncs, fer un estudi exhaustiu sobre aquestes qüestions i moltes més però sense perdre de vista la perspectiva que la presencia de deambulatoris o d'alguna de les característiques de la part occidental dels temples són aspectes que tant podrien procedir de Cluny com d'altres centres a través de models.

Tanmateix, avançant-nos als esdeveniments, no ens hauríem d'estranyar ni de sorprendre si els resultats no fossin gaire eloqüents, perque hem de tenir en compte que J. Puig i Cadafalch ${ }^{43}$ no va saber veure excessives relacions artístiques entre Cluny i Catalunya i els darrers balanços publicats, tampoc ${ }^{44}$.

Pel que fa a l'escultura del segle XII, tampoc s'ha pogut provar cap relació directa amb l'abadia borgonyona. Aquesta, durant bona part del segle, estigue relacionada a Catalunya amb els tallers tolosans que treballaren a l'església de Saint-Étienne i a La Daurade ${ }^{45}$. Tanmateix, el que sí que caldria estudiar més a fons és la possible incidencia artística de Cluny i del seu entorn, tant a nivell estilístic com programàtic, dins les anomenades arts del color, de la pintura i miniatura.

\section{Zona castellano-lleonesa}

Fou durant el regnat de Sancho el Mayor (1004-1035) que algunes construccions de la zona navarro-aragonesa s'allunyaren de l'estil imperant per anunciar el posterior romànic, un fet que potser caldria connectar amb l'obertura a Europa que propicià el mateix monarca. D'aquesta manera, la

\footnotetext{
"I. BANGO TORVISO, La part oriental dels temples de l'abat bisbe Oliba, "Quadems d'Estudis Medicvals", 7-23/24 (1988).

${ }^{42} \mathrm{Cal}$ fer esment de les "Actes del Col.loqui 'Guillaume de Volpiano et l'architecture des rotondes'", que es reuní a Dijon el 1993.

${ }^{43}$ J. PUIG I CADAFALCH, A. DE FAIgUERA, J. GODAY, L'arquilectura romanica a Calalunya, III vols., Burcelona, 1909 i J. PUIG I CADAFALCH, La geografia $i$ els origens del primer art romanic, Barcelona, 1930.

${ }^{4}$ Le paysage monumental de la France autour de l'any mil, X. BARRAL I ALTET, ed. "Col.loqui intemacional Hugues Capet (juliol-setembre 1987), Picard, 1987; i Catalunya $i$ França Meridional a l'entorn de l'any mil, "Actes del col.loqui intemacional Hugues Capet (2-5 de juliol de 1987), Barcelona, 1991.

45. AINAUD DE LASARTE, Moissac et les monastères catalans de la fin du Xe au début du XIle siecle, "Annales du Midi", 75 (1963), pp. 545-549.
} 
catedral de Palencia està sota l'advocació de Sant Antolín, un culte d'origen llenguadocià. Tot i així, i sabent que fou Sancho el Mayor el primer de concedir donacions a l'abadia cluniacenca, no s'ha fet un estudi detallat sobre les possibles relacions entre les construccions per ell patrocinades l'abadia-panteó de San Salvador de Leyre, l'ampliació de l'església de Sant Juan de la Peña o la mateixa catedral de Palencia- i el conjunt monàstic de Cluny II $^{46}$. Hem de pensar, perd, que si la relació de Sancho el Mayor amb l'abadia borgonyona fou del mateix caràcter que la que mantingué l'abat Oliba, una preparatio cluniacensis tal i com l'anomena Ch.J. Bish$\mathrm{ko}^{47}$, Cluny no sembla pas haver pogut exercir una influencia artística directa en els dominis castellans.

El que sí que es deixa intuir en epoca de Fernando I, el primer monarca hispànic a concedir un cens anual a l'abadia borgonyona, és el tarannà imperial d'algunes obres miniades i d'orfebreria, patrocinades pel mateix monarca, que denoten una clara influencia del nord d'Europa, sia alemanya o francesa, que potser només podia ser transmesa via Cluny. L'exemple més fefaent en podria ser el del reliquiari de San Isidoro, una urna d'ànima de fusta sobre la qual es disposen plaquetes de plata, que ha estat relacionada, per l'estil de les figures i pel seu modelat, amb les portes de bronze de Sant Miquel de Hildesheim ${ }^{48}$. Quan John Williams es pregunta com podia haver arribat aquest estil a Espanya, no dubta d'afirmar que és producte de l'estreta relació que en aquells moments mantenien l'abat de Cluny i el monarca del regne de Castella i Lleo; fins i tot, llança la hipdtesi que fos el mateix Hug de Cluny, amb els seus viatges a Alemanya $i$ vincles amb els emperadors otonics, qui en fes d'agent ${ }^{49}$. Durant aquest regnat, tanmateix, l'arquitectura continua presentant una filiació autoctona, d'arrel asturiana, potser amb el proposit de legitimar el poder de Fernando I sobre Lleó i fer-ne el centre del nou imperi en detriment de Castella. D'aquesta manera, la consagració que es realitzà el 1063 de l'antiga església de San Pelayo y San Juan Bautista -aleshores ja San Isidoro- sembla

\footnotetext{
${ }^{46}$ K.J. CONANT (Arquitectura carolingia i románica 800/1200, Madrid, 1982, p. 203) afirma que, malgrat l'anhel d'independència dels monestirs espanyols, alguns, com el de San Juan de la Peña, presenten reminiscències de Cluny II; tanınateix, no les concreta.

${ }^{47} \mathrm{Ch} . J$. BISHKO, op. cit. 1958, pp. 31-135.

${ }^{48} \mathrm{M}$. GÓMEZ MORENO, El arca de las reliquias de San Isidoro, "Archivo Español de Arte y Arqueología" (1932), pp. 205-215.

${ }^{49} \mathrm{~J}$. WILLAMS, op. cil., 1988. pp. 97-98.
} 
correspondre a la reconstruccio, amb materials més duradors, de l'antiga església d'estil asturià.

Quan a l'inici de l'apartat artístic afirmava que s'havia de relativitzar el paper que la historiografia tradicional havia atorgat a Cluny en la difusió de l'art romànic, ho feia sabent que, en el cas de la província de Palencia, a la zona compresa entre els rius Cea i Pisuerga, aquesta afirmació és certa, sobretot durant el darrer terç del segle XI.

La penetracio del romanic madur en Tierra de Campos és indissociable de la penetracio cluniacenca. Serafín Moralejo, en dos encertats estudis ${ }^{\mathbf{s}}$, observa que les primeres manifestacions del romànic ple que s'han conservat a Tierra de Campos es troben en monestirs que, d'una manera o una altra, estigueren vinculats a l'abadia borgonyona. Tanmateix, les primeres mostres romàniques, tant arquitectoniques com escultoriques, d'aquests cenobis cluniacencs -San Isidro de las Dueñas, San Zoil de Carrión, San Benito de Sahagún i San Salvador del Nogal- es troben estretament relacionades amb l'església de San Martín de Frómista que, fins l'any 1118 i a través de San Zoil de Carrión, no ingressà a l'orbita de Cluny. Serafín Moralejo, mitjançant les dades documentals conservades sobre San Martín de Fromista, considera una possible praeparatio cluniacensis amb anterioritat a la data de la seva donacio. Segons el testament de Sancha, vidua de Sancho el Mayor, l'església fou fundada sota el seu patrocini i, com a primer testimoni, hi figurava un tal "Abbas Miró", segurament d'origen català, que serà el futur abat del monestir. D'aquesta manera, es pot afirmar que abans de la seva cessió a San Zoil de Carrión, dins del cenobi de San Martín de Fromista ja es respirava l'esperit de Cluny. No hem de caure en l'error, pero, de pensar que la penetració cluniacenca comportava alguna particularitat formal, perquè les relacions artistiques que s'estableixen entre els monestirs de la província de Palencia esmentats i l'església de San Martín de Frómista són extrapolables a centres monàstics de la Gascunya, província cluniacenca d'on provenien la majoria de monjos destinats als regnes hispànics. L'execució dels vuit capitells d'estil borgonyó del creuer de Santa Maria d'Estíbaliz (Alaba) hauria pogut resultar de la donacio d'aquesta església a un altre priorat de Cluny, Santa Marfa de Nájera, el 1138.

L'aportacio de Cluny a l'art hispànic no ha de buscar-se únicament a nivell de possibles relacions estilístiques o estructurals amb l'abadia mare,

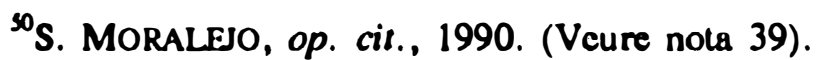


sinó també com la reforma que aixo representà dins de l'orde benedictl, a nivell litúrgic i programàtic. És concretament a l'àrea geogràfica abans ressenyada i per l'estret vincle del poder temporal amb l'abadia cluniacenca on trobem un dels escassos exemples hispanics dels que fins ara s'han estudiat que reflecteix la ideologia concernent a la mort i la resurrecció que desenvolupà Cluny. Es tracta de la tapa del sepulcre d'Alfonso Ansúrez, que fou instal.lada a l'església del monestir de San Benito de Sahagún a la mort d'aquest, l'any 1093. Ha estat de nou Serafín Moralejo qui, per una banda, ha detallat la filiació francesa d'aquesta làpida, vinculant-la també amb el taller principal de San Martín de Frómista que després treballa a la catedral de Jaca $i$, per una altra, ha determinat el significat teologic de cadascun dels elements individuals de la iconografia ${ }^{51}$. Tanmateix, l'historiador gallec no vincula determinats motius iconics i la disposicio general d'aquests amb una possible influencia de l'espiritualitat cluniacenca. Debra Hassig ${ }^{52}$, tenint en compte que Sahagún arribà a ser centre d'una congregació que reuní més de vuitanta-cinc comunitats religioses i que, igual com Cluny, garantia privilegis d'enterrament a la noblesa autoctona a canvi de donacions, no interpreta l'escena representada com l'ascensió de l'ànima del difunt, sinó com la segona resurrecció que simbolitzava l'entrada física a la Jerusalem celestial.

Darrerament, José Luís Senra ha pogut determinar amb precisió les primeres relacions directes entre l'art de Cluny III i dos monestirs benedictins castellans, San Salvador de Oña i San Pedro de Cardeña, agregat a Cluny el $1142^{53}$. La decoració del frontal del refectori de San Salvador de Oña recorda, quant a l'esquema compositiu, disposició i decoració, el cancell del cor de l'església abacial de Cluny III. Altrament, la galeria meridional del claustre i la porta de la sala capitular del cenobi de San Pedro de Cardeña, amb una articulació molt similar a la del frontal del monestir de Oña troben llur paral.lel en la galeria del palau d'Auxerre. Totes dues

\footnotetext{
S1S. MORALEJO, The tomb of Alfonso Ansurez: Its Place and the Role of Sahagun in the Beginnings of Spanish Romanesque Sculpture, a Santiago, Saint-Denis, and Saint Peter: The Reception of the Roman liturgy in León-Castilla in 1080, Nova York, 1985, pp. 63-100.

${ }^{22}$ D. HASSIG, He will Make Alive Your Mortal Bodies: Cluniac Spiritually and the Tomb of Alfonso Ansúrez, "Gesta. Intemational Center of Medieval Art", XXX-1/2 (1988), pp. 93-101.

${ }^{53}$ J.L. Senra Gabriel $i$ Galán, La irrupción borgoñona en la escultura castellana de mediados del siglo XII, "Anuario del Departainento de Historia y Teoria del Arte (U.A.M.)", IV (1992), pp. 35-5i. Vegeu també M. DURUAT, Cluny et l'Espagne, "Bulletin inonumental", 152 (1994), p. 109.
} 
obres borgonyones estan datades dins del primer terç del segle XII, cosa que fa pensar a José Luís Senra que durant les decades centrals del segle XII un planter borgonyó es traslladà als regnes cristians occidentals davant de la demanda artística que presentaven. De mica en mica, aquest nou repertori decoratiu es va anar codificant i progressivament diluït, definirà la tasca escultòrica d'aquest període. De fet, Serafín Moralejo ja havia perfilat la filiació borgonyona de l'escultura del regne de Lleó al segle XII ${ }^{54}$.

Aquestes són algunes de les consideracions que el tema obert de les relacions entre Cluny i la Península Iberica durant els segles XI i XII permet de plantejar: un excel.lent tema de recerca per a un programa de treball comú entre historiadors i historiadors de l'arts'.

\section{RÉSUMÉ}

Bilan géneral des relations historiques et artistiques entre Cluny et la Péninsule Ibérique du $X^{\mathfrak{e}}$ au XII ${ }^{\mathfrak{e}}$ siecle, à la lumiere des recherches récentes. Après avoir analysé les différentes contributions a l'historiographie du sujet, l'auteur nuance beaucoup l'importance des relations directes, constate qu'il y a très peu d'études sur le sujet et assure que les relations sont seulement ponctuelles. Il faudra mettre en place des études monographiques et un programme de recherche particulier sur le rayonnement du prestige de Cluny dans la Péninsule Ibérique. L'article étudie successivement les aspects historiques et artistiques de maniere séparée pour la zone catalane et celle castillane-leonnaise.

\section{SUMMARY}

General balance of the historical and artistic relations between Cluny and the Iberian Peninsula from XIth to XIIth century according to

\footnotetext{
${ }^{54}$ S. MORAlEjo, Esculturas compostelanas del último tercio del siglo XII, "Cuadernos de Estudios Gallegos", XXVIII (1973), pp. 308 i ss.

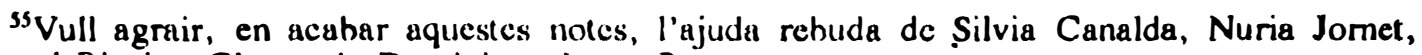
Manuel Riu i, a Cluny, de Doininique logna Prat.
} 
recent research. After analysing the different contributions to the historiography on the subject, the author points out that those relations were only fragmentary and that studies on this subject are scarce. It will be necessary, in the future, to prepare more monographic studies and a special program of research on the diffusion of Cluny's prestige in the Iberian Peninsula. The historical and artistic aspects of the above named period, as far as the Catalan and Castilian areas are concerned, are then dealt with in the article. 